\title{
Resonant and nonresonant vibrational excitation of ammonia molecules in the growth of gallium nitride using laser-assisted metal organic chemical vapour deposition
}

\author{
Hossein Rabiee Golgir, ${ }^{1, a)}$ Yun Shen Zhou, ${ }^{1, a)}$ Dawei Li, ${ }^{1}$ Kamran Keramatnejad, ${ }^{1}$ \\ Wei Xiong, ${ }^{1}$ Mengmeng Wang, ${ }^{1}$ Li Jia Jiang, ${ }^{1}$ Xi Huang, ${ }^{1}$ Lan Jiang, ${ }^{2}$ Jean Francois \\ Silvain ${ }^{3}$ and Yong Feng $\mathrm{Lu}^{1, \mathrm{~b})}$ \\ ${ }^{1}$ Department of Electrical and Computer Engineering, University of Nebraska-Lincoln, Lincoln, NE 68588-0511, USA \\ ${ }^{2}$ School of Mechanical Engineering, Beijing Institute of Technology, 100081, PR China \\ ${ }^{3}$ Institut de Chimie de la Matière Condensée de Bordeaux - ICMCB-CNRS 87, Avenue du Docteur Albert Schweitzer \\ F-33608 Pessac Cedex-France
}

The influence of exciting ammonia $\left(\mathrm{NH}_{3}\right)$ molecular vibration in the growth of gallium nitride $(\mathrm{GaN})$ was investigated by using an infrared laser-assisted metal organic chemical vapor deposition (LMOCVD) method. A wavelength tunable $\mathrm{CO}_{2}$ laser was used to selectively excite individual vibrational modes. Resonantly exciting the $\mathrm{NH}$-wagging mode $\left(v_{2}\right)$ of $\mathrm{NH}_{3}$ molecules at $9.219 \mu \mathrm{m}$ led to a $\mathrm{GaN}$ growth rate of $84 \mu \mathrm{m} / \mathrm{h}$, which is much higher than the reported results. The difference between the resonantly excited and conventional thermally populated vibrational states was studied via resonant and nonresonant vibrational excitation of $\mathrm{NH}_{3}$ molecules. Resonant excitation of various vibrational modes was achieved at 9.219, 10.35 and $10.719 \mu \mathrm{m}$, respectively. Nonresonant excitation was conducted at 9.201 and $10.591 \mu \mathrm{m}$, similar to conventional thermal heating. Compared to nonresonant excitation, resonant excitation noticeably promotes the GaN growth rate and crystalline quality. The full width at half maximum value of the XRD rocking curves of GaN (0002) and GaN (10-12) diffraction peaks decreased at resonant depositions and reached its minimum value of 45 and 53 arcmin, respectively, at the laser wavelength of $9.219 \mu \mathrm{m}$. According to optical emission spectroscopic studies, resonantly exciting the $\mathrm{NH}_{3} v_{2}$ mode leads to $\mathrm{NH}_{3}$ decomposition at room temperature, reduces the formation of the TMGa: $\mathrm{NH}_{3}$ adduct, promotes the supply of active species in $\mathrm{GaN}$ formation, and therefore results in the increased $\mathrm{GaN}$ growth rate.

\section{INTRODUCTION}

Gallium nitride $(\mathrm{GaN})$ has attracted enormous attention as a versatile functional material for high-power and high frequency electronics, short-wavelength optical devices (such as light emitting diodes, lasers, and photodetectors), and other optoelectronics. ${ }^{1-3}$ Synthetic techniques of high growth rates are in demand for the scalable production of quality GaN films to satisfies the steadily increasing quest. ${ }^{4-8}$ Additionally, a high growth rate helps reducing the cycle time in device fabrication. Various approaches such as the hydride vapor phase epitaxy (HVPE), ammonothermal growth, and Na-flux method have been

\footnotetext{
a) These authors contributed equally to this work.

b) Author to whom correspondence should be addressed. Tel.: +1-402-472-8323. Fax: +1-402-472-4732. E-mail: ylu2@unl.edu.
} 
developed to achieve high GaN growth rates. ${ }^{9-11}$ However, achieving prolonged growth with a high growth rate is still a challenge.

High-quality commercial GaN films are usually grown by the metalorganic chemical vapor deposition (MOCVD) technique on expensive substrates such as sapphire and $\mathrm{SiC}$ substrates at a growth rate around $2 \mu \mathrm{m} / \mathrm{h} .{ }^{12-14}$ Recently, interests in the epitaxial growth of thick GaN films on Si substrates arose for scalable production of power-switching devices at an affordable cost. ${ }^{6,8}$ However, the MOCVD technique is accompanied with a parasitic reaction between the precursors at high temperatures, which restricts the growth rates and impairs the epitaxial growth of thick GaN films. ${ }^{13-16}$ In addition, the high growth temperatures $\left(\sim 900-1200{ }^{\circ} \mathrm{C}\right)$ lead to $\mathrm{GaN}$ decomposition and nitrogen reevaporation therefore result in reduced GaN growth rates and degraded crystalline quality. ${ }^{17,18}$ Moreover, there is a series of Ga-Si reactions at elevated temperatures that could directly deter the growth of $\mathrm{GaN}$ on $\mathrm{Si}^{19}$ However, a high reaction temperature is required for effective $\mathrm{NH}_{3}$ decomposition and overcoming the energy barriers on precursor adsorption and surface adatom migration. ${ }^{13-16}$ Ultraviolet laser-induced MOCVD growth of group-III nitrides was developed ${ }^{20,21}$ with the potential to overcome these disadvantages and was principally intended to provide the reactive radicals $\mathrm{Ga}$ and $\mathrm{N}$ by photolyzing corresponding precursors at low substrate temperatures. However, the density of the reactive $\mathrm{N}$-containing fragments from $\mathrm{NH}_{3}$ was not high enough even at high volume ratios and GaN growth rate was low. To address the challenges without introducing hetero catalysts, we have recently developed an infrared laser-assisted MOCVD (LMOCVD) method to achieve GaN growth at a substrate temperature as low as $250{ }^{\circ} \mathrm{C} .{ }^{22}$ Selective $\mathrm{NH}_{3}$ decomposition at room temperatures was realized by resonantly exciting the rotational-vibrational transition of the $\mathrm{NH}$-wagging mode at $1084.63 \mathrm{~cm}^{-1}$ using a $\mathrm{CO}_{2}$ laser beam which was allowed to travel along the path parallel to the substrate surface. A high GaN growth rate of up to $12 \mu \mathrm{m} / \mathrm{h}$ was achieved by LMOCVD, which was $\sim 4.6$ times faster than that of conventional MOCVD without using of laser. However, there are unanswered questions in understanding the roles of vibrational excitation in $\mathrm{NH}_{3}$ decomposition and $\mathrm{GaN}$ formation. There are six vibrational modes and numerous vibrational bands in $\mathrm{NH}_{3}$ molecules. Will vibrational excitation of each mode contribute equally to the $\mathrm{NH}_{3}$ decomposition and GaN growth? How will each mode impact the $\mathrm{NH}_{3}$ decomposition and GaN growth?

In this study, we investigated the influence of exciting $\mathrm{NH}_{3}$ molecular vibration in the growth of GaN on $\mathrm{Si}(100)$ substrates using a LMOCVD method. Based on the available irradiation lines, the $\mathrm{NH}_{3} \mathrm{NH}$-wagging modes at $932.51\left(v_{2+}\right)$ and 968.32 $\mathrm{cm}^{-1}\left(v_{2}-\right)$, and the $\mathrm{NH}$ rotational-vibrational transition at $1084.63 \mathrm{~cm}^{-1}$ were resonantly excited leading to significantly improved GaN growth rates. Compared to laser-induced thermal heating at nonresonant wavelengths, the resonant 
excitations lead to more effective $\mathrm{NH}_{3}$ decomposition, higher concentrations of active species, higher GaN deposition rates, and better GaN crystalline quality.

\section{EXPERIMENT}

\section{A. Sample preparation}

The schematic experimental setup of a home-built LMOCVD system is shown in Figure 1. GaN films were grown on p-type $\mathrm{Si}(100)$ substrates. From the point of view of integrating GaN devices with silicon technology, the Si(100) substrate is preferred because $\mathrm{Si}(100)$ is the most widely used in silicon mainstream technology. The Si substrates (10 $\times 10 \mathrm{~mm}^{2}$ ) were etched with $10 \%$ hydrofluoric to remove oxide layers, cleaned and dried before loading into the LMOCVD chamber. Trimethylgallium (TMGa) and $\mathrm{NH}_{3}$ were used as the Ga and $\mathrm{N}$ precursors, respectively. The LMOCVD chamber was evacuated to a base pressure of $1 \times 10^{-3}$ Torr. Then, laser thermal cleaning of Si substrates was carried out at $900{ }^{\circ} \mathrm{C}$ under $\mathrm{H}_{2}$ flow for 5 min to remove the native oxide on the substrate surface followed by nitridation at $750{ }^{\circ} \mathrm{C}$. The nitridation was lasted for $5 \mathrm{~min}$ under $54 \mathrm{mmol} / \mathrm{min} \mathrm{NH}_{3}$ flow at a reactor pressure of 100 Torr. It has been widely reported that a silicon nitride layer is formed due to the nitridation surface treatment process on the silicon substrate. ${ }^{23,24}$ Nitridation of Si surface helps to release strain in GaN-on-Si growth and favours the growth of wurtzite GaN. ${ }^{25-27}$

The molar flow rate of $\mathrm{NH}_{3}$ was maintained at $54 \mathrm{mmol} / \mathrm{min}$. The TMGa was carried into the growth chamber using a nitrogen carrier gas $\left(\mathrm{N}_{2}\right)$ at a molar flow rate of $88 \mu \mathrm{mol} / \mathrm{min}$. The chamber pressure during the growth process was maintained at $\sim 10$ Torr. A continuous-wave wavelength-tunable $\mathrm{CO}_{2}$ laser (PRC Inc., $\left.9.2-10.9 \mu \mathrm{m}\right)$ was used as the irradiation source, achieving reactant excitation and substrate heating. Based on the available emission lines of the $\mathrm{CO}_{2}$ laser, the $\mathrm{NH}$-wagging modes $\left(v_{2}\right.$, at $932.51,968.32$, and $\left.1084.71 \mathrm{~cm}^{-1}\right)$ of $\mathrm{NH}_{3}$ molecules were selected to be resonantly excited at corresponding laser wavelengths of $10.719,10.350$, and $9.219 \mu \mathrm{m}$. Two other wavelengths at 9.201 and $10.591 \mu \mathrm{m}$ were selected as nonresonant wavelength references realizing only conventional laser heating. GaN nucleation layers (40 - $60 \mathrm{~nm}$ in thickness) were deposited at $500{ }^{\circ} \mathrm{C}$ for 30 seconds followed by epilayer growth at $750{ }^{\circ} \mathrm{C}$ for $5 \mathrm{~min}$. The laser incident power was tuned to keep the substrate temperature same for all GaN samples grown at different laser wavelengths. The substrate temperature was monitored using a pyrometer (Omega, OS3752). 


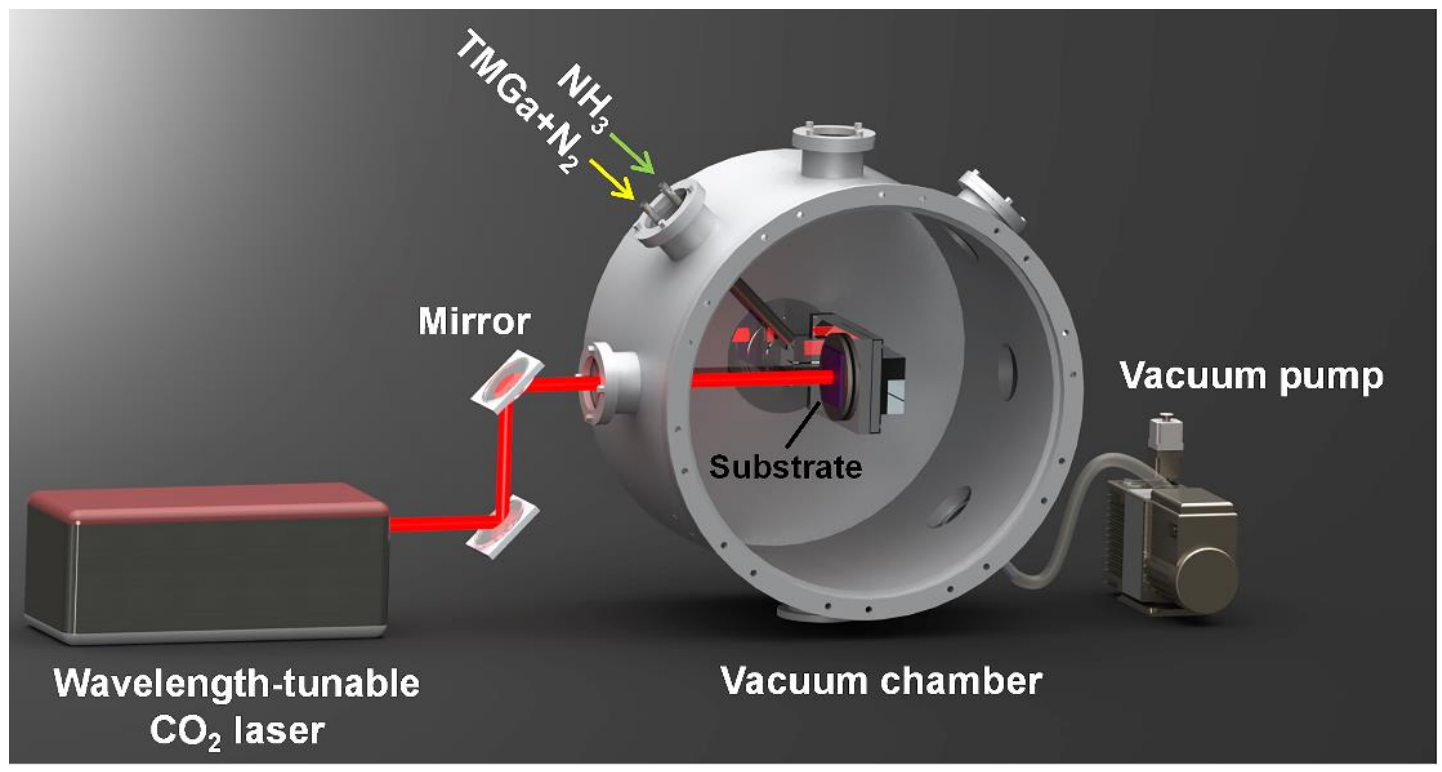

FIG. 1. The schematic of the LMOCVD system.

\section{B. $\mathrm{NH}_{3}$ absorption spectrum within the $\mathrm{CO}_{2}$ laser wavelength range}

In order to find appropriate wavelengths achieving resonant vibrational excitation of $\mathrm{NH}_{3}$ molecules, it is essential to found out available emission lines matching $\mathrm{NH}_{3}$ molecular vibrational modes within the $\mathrm{CO}_{2}$ laser wavelength range (9.2 - $10.8 \mu \mathrm{m}) . \mathrm{NH}_{3}$ absorption spectrum within the $\mathrm{CO}_{2}$ laser wavelength range was measured in a vacuum chamber with an absorption path length of $40.64 \mathrm{~cm}$. The chamber was evacuated to a base pressure of $1 \times 10^{-3}$ Torr. Gaseous $\mathrm{NH}_{3}$ was subsequently introduced into the chamber and reach a pressure of 10 Torr. The incident laser power was kept at $220 \mathrm{~W}$. A power meter was used to measure the laser power before and after passing through the chamber. The drop in laser power was calculated as the absorption percentage.

Three strong absorption peaks were observed at 9.219, 10.35, and $10.719 \mu \mathrm{m}$ (resonant wavelengths), corresponding to the NH-wagging modes $\left(v_{2}\right)$ at $1084.63,968.32$, and $932.51 \mathrm{~cm}^{-1}$, respectively. ${ }^{22,28}$ Among all six vibrational modes of $\mathrm{NH}_{3}$ molecules, the $\mathrm{NH}$-wagging mode is strongly infrared active. $\mathrm{A} \mathrm{NH}_{3}$ molecule in the $\mathrm{NH}$-wagging mode vibrates in an umbrella inversion way. ${ }^{29,30}$ Due to the barrier that the nitrogen atom encounters on its travel through the proton plane, the vibrational level is split into two components at $932.51\left(v_{2^{+}}\right)$and $968.32 \mathrm{~cm}^{-1}\left(v_{2^{-}}\right)$which correspond to the observed absorption peaks at 10.719 and $10.35 \mu \mathrm{m}$, respectively. ${ }^{28-32}$ The strongest absorption peak at $9.219 \mu \mathrm{m}$ is ascribed to the NH rotational-vibrational transition at $1084.63 \mathrm{~cm}^{-1}\left[5(\mathrm{~J}) \rightarrow 6\left(\mathrm{~J}^{\prime}\right), \mathrm{K}=0\right]$. 


\section{Characterization}

Surface morphologies of the GaN films were studied using a field-emission scanning electron microscope (FESEM, Hitachi S4700). The qualities of GaN films were examined using a Raman microscope (Renishaw inVia H 18415, Argon ion laser, $\lambda=514 \mathrm{~nm}$ ) and X-ray diffractometer (Rigaku D/Max B diffractometer, Co K $\alpha \lambda=1.788 \AA$ ). The doping type, carrier concentration and mobility of the GaN films were obtained via the Van der Pauw method at room temperature. The optical emission spectra (OES) of laser irradiated $\mathrm{NH}_{3}$ were taken in open air using a spectrometer (Shamrock SR-303i-A, Andor Technology) coupled with an intensified charged coupled device (ICCD) (iStar DH712, Andor Technology) as shown in Figure 2. The IR laser beam was focused to a diameter around $1 \mathrm{~mm}$ using a ZnSe convex lens $(\mathrm{f}=25.4 \mathrm{~cm})$. A welding torch with a nozzle diameter of $1.5 \mathrm{~mm}$ was used to introduce the $\mathrm{NH}_{3}$ gas at a flowrate of $50 \mathrm{sccm}$. The $\mathrm{CO}_{2}$ laser beam was directed perpendicularly to the $\mathrm{NH}_{3}$ flow. The laser incident power density was fixed at $1.4 \times 10^{4} \mathrm{~W} / \mathrm{cm}^{2}$ for all laser wavelengths. All spectra were taken with a vertical collecting length of $0.5 \mathrm{~mm}$ along the emission, centred at the tip of the emission, and with a horizontal slit width of $30 \mu \mathrm{m}$ centred at the tip apex of the emission. A background spectrum captured before collecting the emission spectra was subtracted from all spectra.

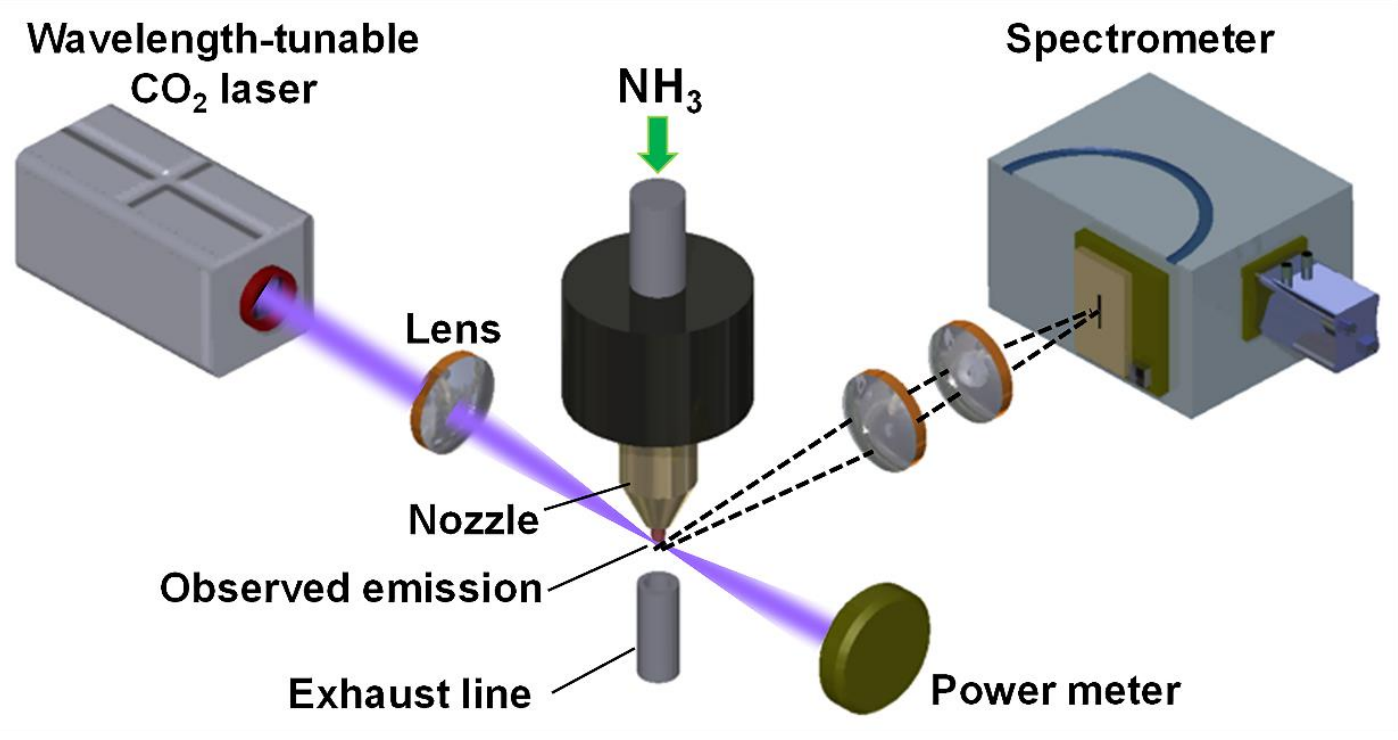

FIG. 2. Schematic experimental setup for the OES measurements in open air. 


\section{RESULT AND DISCUSSION}

\section{A. FESEM images of the GaN films}

The morphologies and grain sizes of the GaN films deposited at different laser wavelengths are shown in Figure 3(a) - 3(e), respectively. Crystalline GaN films containing highly oriented grains along the c-axis with hexagonal facets are observed, indicating the formation of wurtzite $\mathrm{GaN}$ films on the $\mathrm{Si}(100)$ substrates. Generally, a mixture of cubic and hexagonal $\mathrm{GaN}$ tends to grow on $\mathrm{Si}(100)$ substrates because the (001) plane of $\mathrm{Si}$ possesses a fourfold symmetry. ${ }^{23-27}$ However, the nitridation process promotes the silicon nitride formation and prohibits cubic GaN nucleation. Therefore, hexagonal GaN dominates the GaN growth. ${ }^{23-27}$

It is generally accepted that grain boundaries impacts negatively on the electrical and optical properties of GaN films. ${ }^{33,34}$ Increasing grain sizes leads to reduced grain boundaries and results in a reduced amount of defects and stress. Therefore, the crystalline quality and optical properties of GaN films are improved accordingly. ${ }^{33,34}$ Figure 3(f) compares the average grain sizes of the GaN films grown at different laser wavelengths. As shown in Figure 3(a) and 3(d), GaN grains with average grain sizes of 1.0 and $2.1 \mu \mathrm{m}$ are obtained at nonresonant wavelengths of 9.201 and $10.591 \mu \mathrm{m}$, respectively. The average grain sizes increase to 4.0, 3.8, and $3.1 \mu \mathrm{m}$ at resonant wavelengths 9.219 , 10.350, and 10.719 $\mu \mathrm{m}$, respectively, as shown in Figure 3(b), 3(c), and 3(e).

The cross-sectional SEM images of the GaN films deposited at non- $(9.201 \mu \mathrm{m})$ and resonant wavelengths $(9.219$ $\mu \mathrm{m}$ ) for 5 minutes are exhibited in Figure 4(a) and 4(b), respectively. The resonant deposition, Figure 4(b), results in a thicker $\mathrm{GaN}$ film $(7 \mu \mathrm{m})$ than the nonresonant deposition, Figure 4(a), indicating a higher growth rate (around 2.7 times higher) at the resonant deposition. Figure 4(c) compares the deposition rates obtained at all five wavelengths. It is obvious that resonant depositions result in higher GaN growth rates than nonresonant depositions. The highest growth rate $(84 \mu \mathrm{m} / \mathrm{h})$ is achieved at $9.219 \mu \mathrm{m}$, which is $\sim 42$ times higher than that of conventional MOCVD (2 $\mu \mathrm{m} / \mathrm{h}) .{ }^{6,12,13}$ Although not as significant as those obtained under the resonant wavelengths, promoted GaN growth rates are also observed at nonresonant wavelengths, 9.201 and $10.591 \mu \mathrm{m}$, and are ascribed to the coupled energy via laser irradiation. However, the same amount of energy coupled at different wavelengths yields obviously divergent results as observed in Figure 3(f) and 4(c). 
(a) $\lambda=9.201 \mu \mathrm{m}$

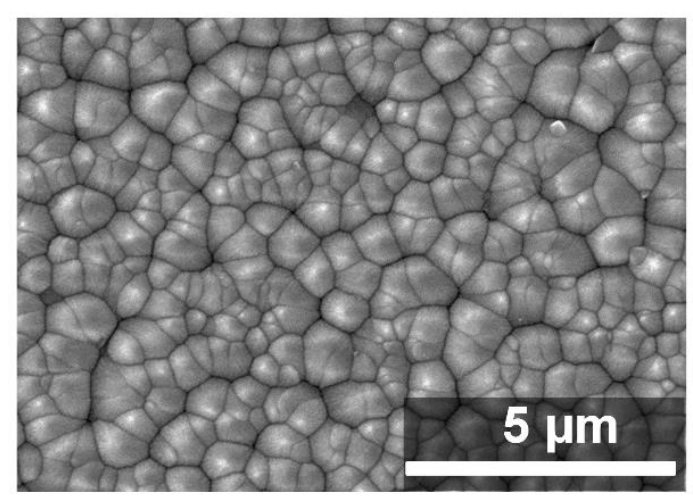

(c) $\lambda=10.350 \mu \mathrm{m}$

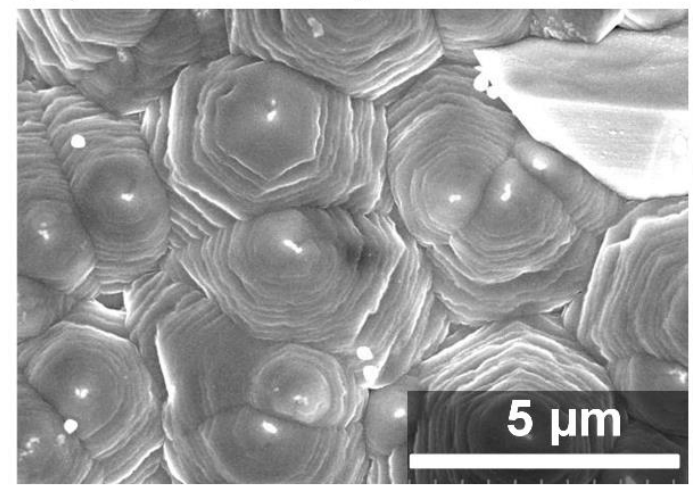

(e) $\lambda=10.719 \mu \mathrm{m}$

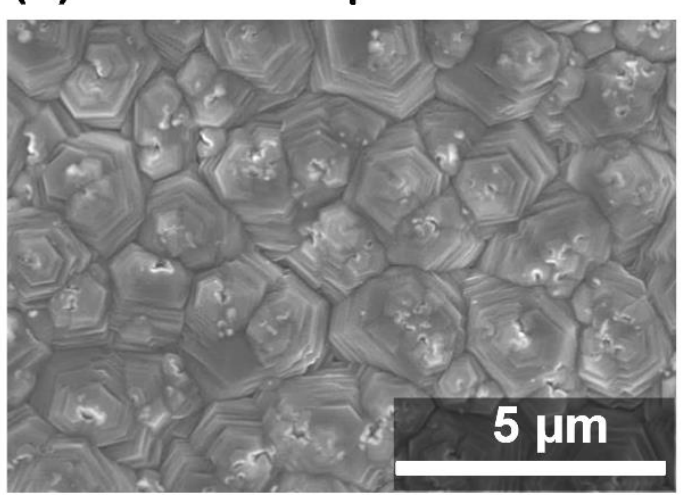

(b) $\lambda=9.219 \mu \mathrm{m}$

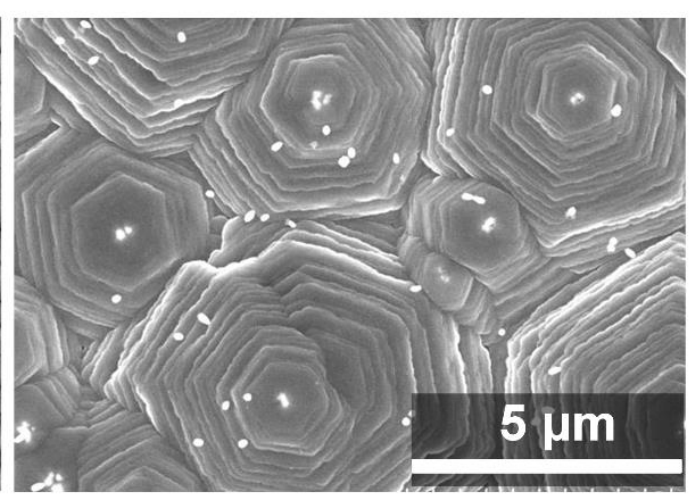

(d) $\lambda=10.591 \mu \mathrm{m}$
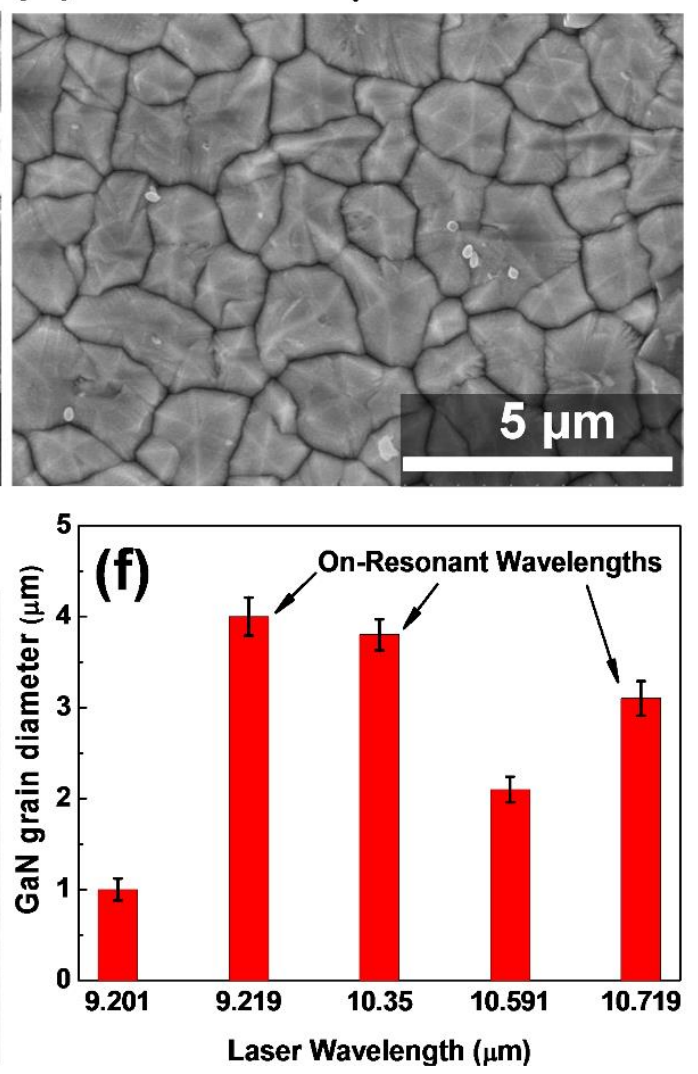

FIG. 3. SEM images of GaN films deposited on Si (100) at excitation laser wavelength of (a) $9.201 \mu \mathrm{m}$, (b) $9.219 \mu \mathrm{m}$, (c) $10.350 \mu \mathrm{m}$, (d) $10.591 \mu \mathrm{m}$, and (e) $10.719 \mu \mathrm{m}$, respectively. (f) A chart showing average GaN grain sizes obtained at different laser wavelengths. 

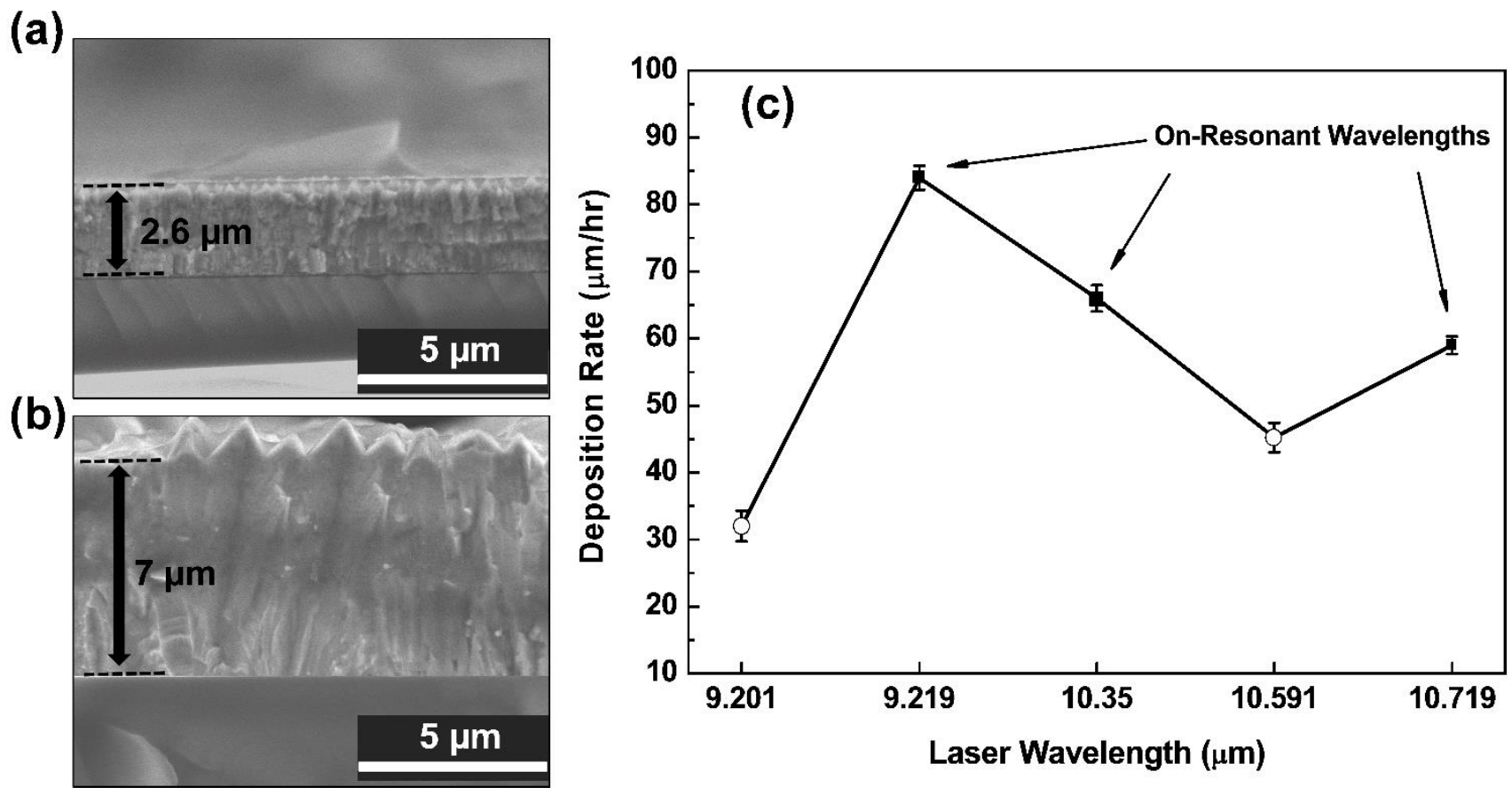

FIG. 4 Cross-sectional SEM images of GaN films deposited on $\mathrm{Si}$ (100) for 5 minutes with $\mathrm{CO}_{2}$ laser excitation at (a) nonresonant wavelength of $9.201 \mu \mathrm{m}$ and (b) resonant wavelength of $9.219 \mu \mathrm{m}$. (c) GaN deposition rate plotted as a function of laser wavelength.

\section{B. Raman spectra of the GaN films}

Raman spectroscopy is a powerful method evaluating the quality and residual stress of GaN films. ${ }^{35}$ Raman spectroscopic studies were conducted under a $\mathrm{Z}(\mathrm{X}, \mathrm{X}) \overline{\mathrm{Z}}$ backscattering geometry, where $\mathrm{Z}$ and $\overline{\mathrm{Z}}$ represent the projection direction of the incoming and scattered light, and $\mathrm{X}$ represents the polarization direction of the incoming and scattered light. Figure 5(a) shows the Raman spectra of the GaN films grown at different laser wavelengths. Two prominent Raman shifts at around 567 and 733 $\mathrm{cm}^{-1}$ are observed from all samples, corresponding to the $\mathrm{GaN}_{2 \mathrm{H}}$ and $\mathrm{A}_{1}(\mathrm{LO})$ phonon modes, respectively. These modes originate from allowed vibrational states in the wurtzite $\mathrm{GaN}$ epitaxial layer. ${ }^{35}$ The exact positions of the $\mathrm{GaN}_{2 \mathrm{H}}$ phonon peak of the samples were summarized in Table I.

It is well known that the $\mathrm{E}_{2 \mathrm{H}}$ mode in the GaN Raman spectra reflects crystalline quality and stress of the crystals. ${ }^{35}$ The $\mathrm{E}_{2 \mathrm{H}}$ peaks shift to lower wave-numbers (red-shift) compared with that of the strain-free $\mathrm{GaN}$ at $567.8 \mathrm{~cm}^{-1}$. The shifts of the $\mathrm{E}_{2 \mathrm{H}}$ peak are observed to be around 1.7, 1, 1.3,1.3 and $1.2 \mathrm{~cm}^{-1}$ for the samples grown at laser wavelengths of 9.201, 9.219, 10.35, 10.591 and $10.719 \mu \mathrm{m}$, respectively. The red-shift indicates the tensile stress in the GaN films. The stress of the GaN epilayers can be calculated using the following equation: ${ }^{36} \sigma=\Delta \omega / 4.3$, where $\sigma$ is the biaxial stress and $\Delta \omega$ is the $\mathrm{E}_{2 \mathrm{H}}$ phonon peak shift. Corresponding tensile stresses are calculated and summarized in Table I. The Raman spectra indicate that the GaN films grown at laser wavelengths of $9.219 \mu \mathrm{m}$ exhibit the lowest stress. 
Moreover, as observed in Figure 5(a), the $\mathrm{E}_{2 \mathrm{H}}$ peak is much stronger in the resonant samples $(9.219,10.35$, and $10.719 \mu \mathrm{m})$ than in the nonresonant samples $(9.201$ and $10.591 \mu \mathrm{m})$, indicating better crystalline quality of the resonant samples. The strongest $\mathrm{E}_{2 \mathrm{H}}$ peak is observed when resonantly excited at $9.219 \mu \mathrm{m}$, denoting the highest GaN crystalline quality. The fullwidth-at-half-maximum (FWHM) values of the $\mathrm{E}_{2 \mathrm{H}}$ peaks of the GaN samples were summarized in Table I. A narrow $\mathrm{E}_{2 \mathrm{H}}$ peak, i.e. a low FWHM value, indicates a better crystalline quality. According to Table I., it is obvious that FWHMs of resonant samples are lower than those of nonresonant samples. The lowest FWHM, $9.3 \mathrm{~cm}^{-1}$, is observed in the resonant sample excited at $9.219 \mu \mathrm{m}$, indicating the highest GaN crystalline quality.

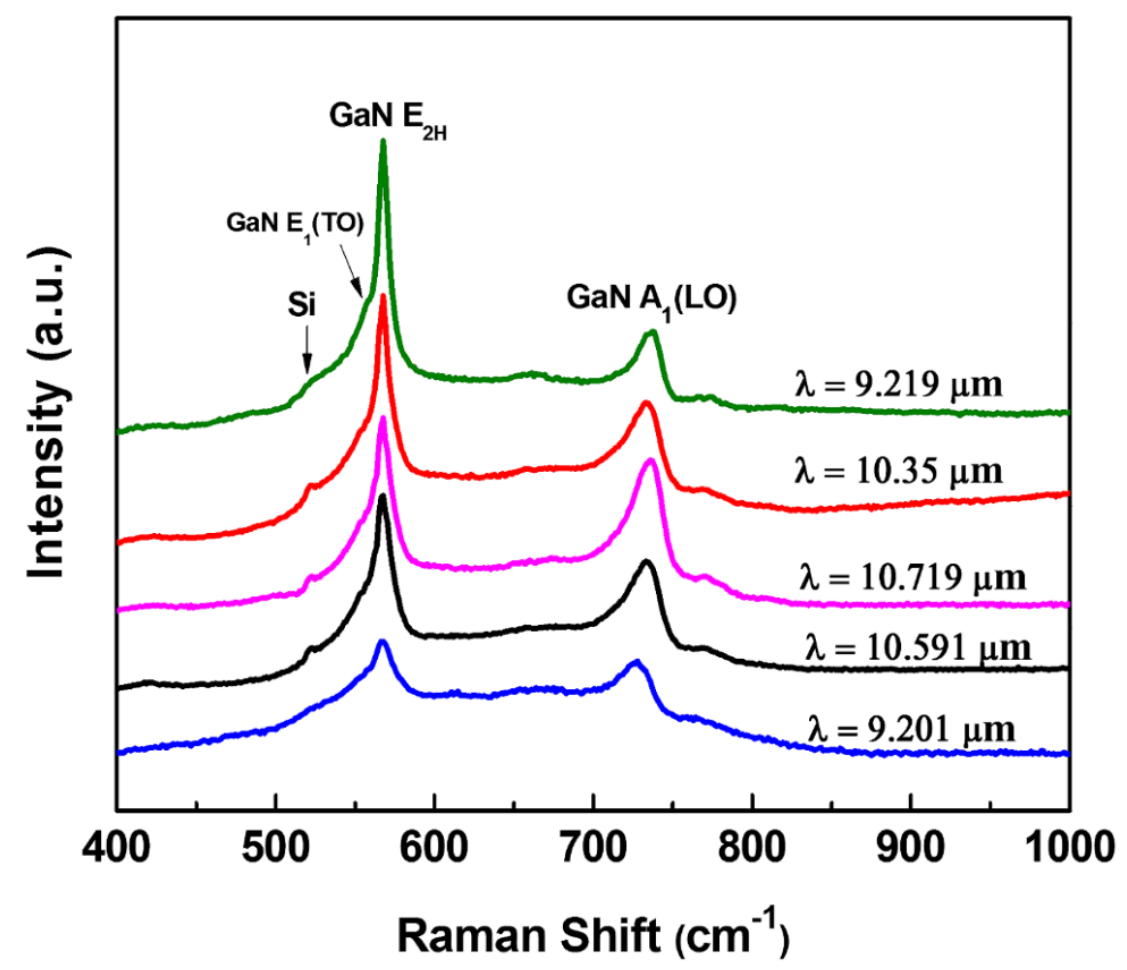

FIG. 5. Raman spectra of the GaN films grown at resonant $(9.219,10.35$, and $10.719 \mu \mathrm{m})$ and nonresonant $(9.201$ and $10.591 \mu \mathrm{m})$ wavelengths.

TABLE I. Summary of GaN films characterization grown on Si (100) substrates at different laser wavelengths.

\begin{tabular}{|c|c|c|c|c|c|c|c|c|}
\hline Sample & $\begin{array}{c}\text { Laser } \\
\text { wavelength } \\
(\mu \mathrm{m})\end{array}$ & $\begin{array}{r}\text { Average } \\
\text { grain } \\
\text { sizes }(\mu \mathrm{m})\end{array}$ & $\begin{array}{l}\text { Growth rate } \\
\qquad(\mu \mathrm{m} / \mathrm{hr})\end{array}$ & $\begin{array}{c}\mathrm{GaN} \mathrm{E}_{2 \mathrm{H}} \\
\text { peak } \\
\text { position } \\
\left(\mathrm{cm}^{-1}\right) \\
\end{array}$ & $\sigma(\mathrm{GPa})$ & $\begin{array}{c}\mathrm{GaN} \mathrm{E}_{2 \mathrm{H}} \\
\text { peak } \\
\mathrm{FWHM} \\
\left(\mathrm{cm}^{-1}\right)\end{array}$ & $\begin{array}{c}\text { GaN }(0002) \\
\text { peak } \\
\omega-\mathrm{FWHM} \\
(\operatorname{arcmin})\end{array}$ & $\begin{array}{c}\mathrm{GaN}(10-12) \\
\text { peak } \\
\omega-\mathrm{FWHM} \\
(\operatorname{arcmin})\end{array}$ \\
\hline $\mathrm{I}$ & 9.201 & 1 & 32 & 566.1 & 0.395 & 19 & 92 & 99 \\
\hline II & 9.219 & 4 & 84 & 566.8 & 0.233 & 9.3 & 39 & 43 \\
\hline III & 10.350 & 3.8 & 66 & 566.5 & 0.302 & 10.1 & 45 & 53 \\
\hline IV & 10.590 & 2.1 & 45 & 566.5 & 0.302 & 11.9 & 60 & 67 \\
\hline $\mathrm{V}$ & 10.719 & 3.1 & 59 & 566.6 & 0.280 & 11.2 & 55 & 61 \\
\hline
\end{tabular}




\section{XRD characterization of the GaN films}

Figure 6(a) and 6(b) exhibit the XRD diffraction curves of the GaN films obtained at 9.219 (resonant wavelength) and 9.201 $\mu \mathrm{m}$ (nonresonant wavelength), respectively. The XRD peaks at around $40.2^{\circ}$ and $87.02^{\circ}$ are observed in both curves and attributed to the GaN $\{0001\}$ family planes. These peaks correspond to the (0002) and (0004) orientations of wurtzite GaN, respectively, indicating a high c-axis orientation of the GaN films deposited on the $\mathrm{Si}(100)$ substrates. ${ }^{37} \mathrm{It}$ is observed from Figure 6(a) and 6(b) that the GaN XRD peaks are much stronger in the resonant sample than those in the nonresonant sample, which is attributed to the improved crystalline quality.

The GaN (0002) rocking curves of the GaN films deposited at the resonant $(9.219 \mu \mathrm{m})$ and nonresonant $(9.201 \mu \mathrm{m})$ wavelengths are exhibited in Figure 6(c) and 6(d), respectively. FWHM values of the rocking curves of (0002) symmetric and (10-12) asymmetric diffraction peaks were summarized in Table I. It is well known that the FWHM of XRD in the (0002) reflection reveals information about the out-of-plane misorientation of domains (tilt) while the FWHM of the GaN (10-12) peak is sensitive to both tilt and twist. Thus, the FWHM of the (0002) peak is usually used to evaluate the screw or mixed threading dislocations (TDs) density and the FWHM of XRD in the (10-12) reflection corresponds to the lattice distortion from all components of the TDs including edge, screw and mixed screw-edge dislocations. ${ }^{37,38}$ Low FWHM values indicate low TDs density and better crystalline quality.

As shown in Table I, (0002) FWHM values of 92 and 60 arcmin and (10-12) FWHM values of 99 and 67 arcmin are observed for the GaN samples deposited at the nonresonant wavelengths of 9.201 and $10.591 \mu$ m, respectively. For the GaN film deposited with resonant excitation, the FWHMs of (0002) are 39, 45, and 55 arcmin and the FWHMs of (10-12) are 43, 53, and 61 arcmin at resonant wavelengths of 9.219, 10.350, and $10.719 \mu \mathrm{m}$, respectively. The distinctive FWHMs decrease in resonant samples compared to those with nonresonant samples indicates improved GaN crystalline quality and reduced TDs density by using resonant excitation. However, the crystalline quality of GaN films are inferior to that reported for conventional MOCVD ${ }^{6}$ which is attributed to the high growth rates of $\mathrm{GaN}$, large crystal lattice mismatch (16.9\%), and thermal coefficient

of expansion mismatch $(113 \%)$ between the GaN epilayer and the Si substrate. ${ }^{6,8}$ Further investigations are underway to improve GaN crystalline quality while maintain the high growth rates. 

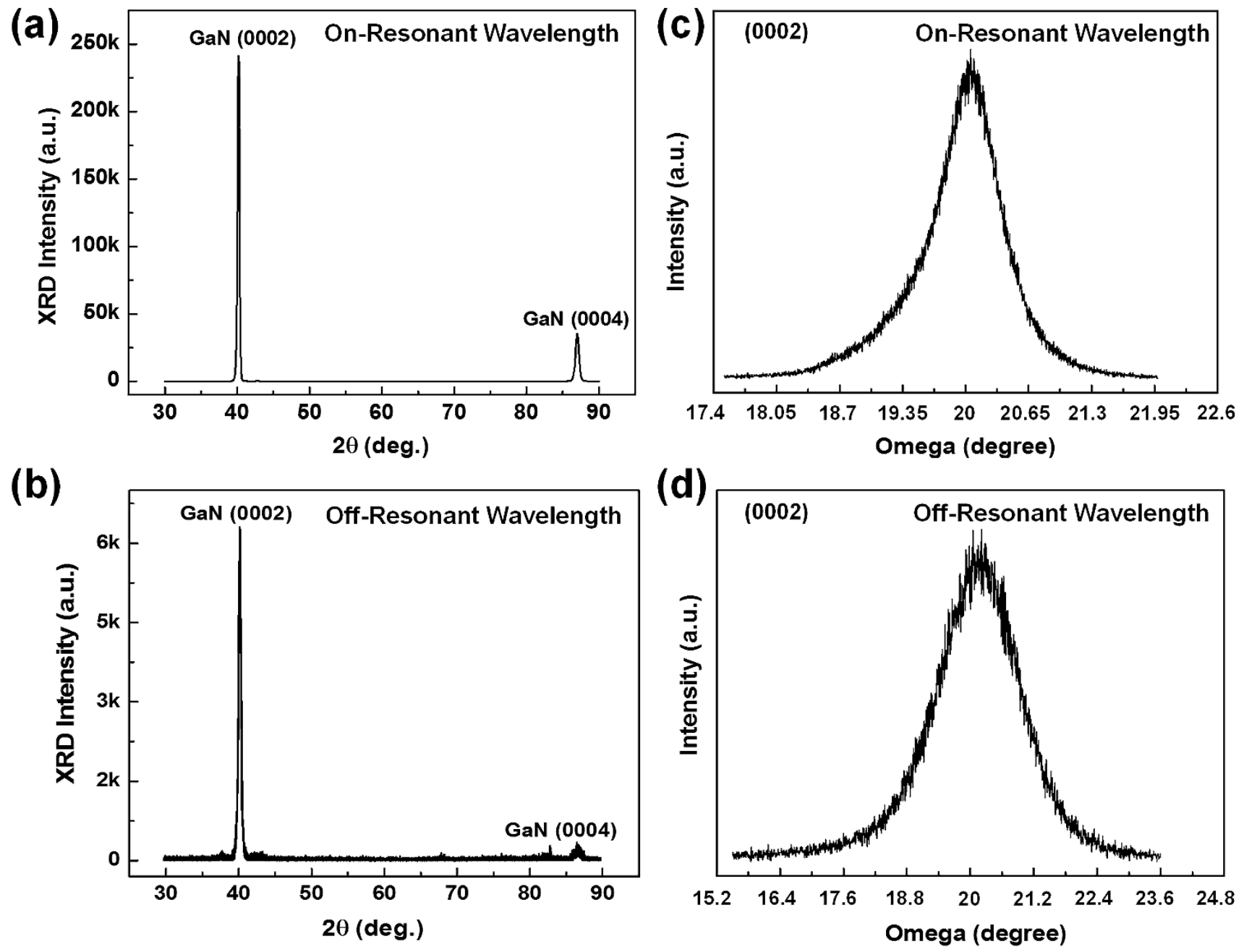

FIG. 6. X-ray diffraction curves of GaN films deposited at (a) resonant wavelength of $9.219 \mu \mathrm{m}$ and (b) nonresonant wavelength of 9.201 $\mu \mathrm{m}$ (X-ray diffractometer: Rigaku D/Max B diffractometer, Co K $\alpha \lambda=1.788 \AA$ ). Rocking curves of (0002) diffraction peaks of $\mathrm{GaN}$ films deposited at (c) resonant wavelength of $9.219 \mu \mathrm{m}$ and (d) nonresonant wavelength of $9.201 \mu \mathrm{m}$.

\section{Hall measurement of the GaN films}

Hall measurements using the Van der Pauw method were conducted to characterize carrier concentrations and mobilities of the GaN films deposited at resonant $(9.219 \mu \mathrm{m})$ and nonresonant $(9.201 \mu \mathrm{m})$ wavelengths. Both GaN films were demonstrated to be n-type semiconductors. Corresponding carrier concentrations and mobilities are $8.27 \times 10^{17} \mathrm{~cm}^{-3}$ and $299.5 \mathrm{~cm}^{2} / \mathrm{Vs}$ for the resonant sample, and $4.9 \times 10^{18} \mathrm{~cm}^{-3}$ and $119.1 \mathrm{~cm}^{2} / \mathrm{Vs}$ for the nonresonant sample. The relatively high carrier concentration indicates a high concentration of unintentionally doped impurities. However, the resonant sample possesses a lower carrier concentration but higher mobility, compared to the nonresonant sample. 


\section{MECHANISM OF THE RESONANT VIBRATIONAL EXCITATION}

\section{A. Optical emission spectra of $\mathrm{NH}_{3}$ under laser irradiation.}

According to above experimental results, two points are clearly demonstrated. The first is that resonant vibrational excitation can significantly promote $\mathrm{GaN}$ growth rates and improve $\mathrm{GaN}$ crystalline quality when comparing to conventional thermal heating and nonresonant laser irradiation. The second is that the same amount of energy coupled into different vibrational states lead to diverse results. In this study, the resonant excitation of the NH rotational-vibrational transition at $1084.63 \mathrm{~cm}^{-1}[5(\mathrm{~J})$

$\left.\rightarrow 6\left(\mathrm{~J}^{\prime}\right), \mathrm{K}=0\right]$ leads to the highest $\mathrm{GaN}$ growth rate, best crystalline quality, and highest carrier mobility. To understand the reasons behind the difference, optical emission spectroscopic (OES) investigations were carried out to study the evolution of $\mathrm{NH}_{3}$ molecules under laser irradiation at resonant and nonresonant wavelengths in open air. Figure 7 shows optical images of the $\mathrm{NH}_{3}$ flows under laser irradiation at different wavelengths. Stronger emissions are observed from $\mathrm{NH}_{3}$ flows when irradiated at resonant wavelengths (i.e. 9.219, 10.350, and $10.719 \mu \mathrm{m}$ ) than those at nonresonant wavelengths (i.e. 10.591 and $9.201 \mu \mathrm{m})$. The shape and brightness of the laser-induced plasma reflect dissociation of $\mathrm{NH}_{3}$ molecules under the laser irradiation. According to Figure 7, resonant excitations lead to $\mathrm{NH}_{3}$ flows of brighter colors and expanded diameters due to accelerated $\mathrm{NH}_{3}$ dissociation, promoted chemical reactions, and increased reactive species concentrations. ${ }^{39}$ The brightest and strongest $\mathrm{NH}_{3}$ flow is observed under the resonant excitation at $9.219 \mu \mathrm{m}$.

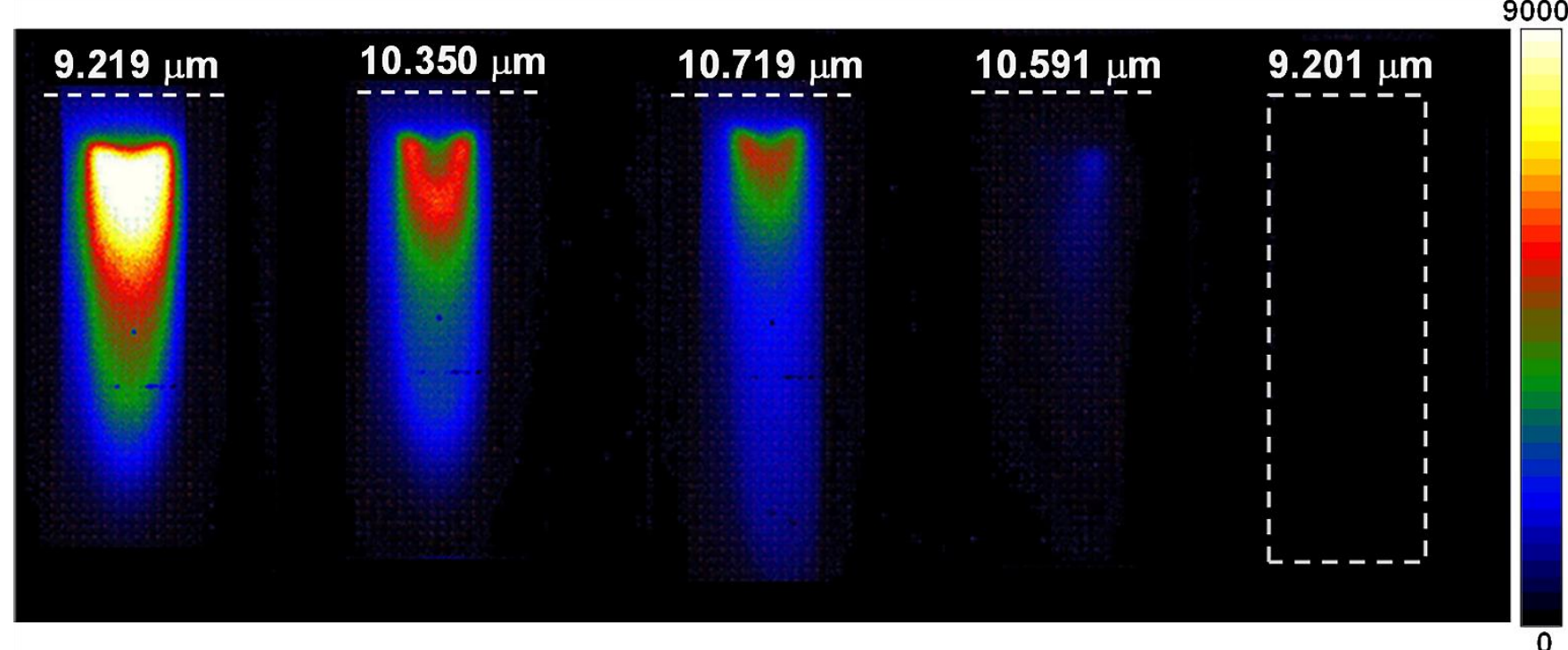

FIG.7. Optical images of $\mathrm{NH}_{3}$ flows when irradiated at different laser wavelengths in open air.

OES spectra of the laser-irradiated $\mathrm{NH}_{3}$ are shown in Figure 8. Emissions from $\mathrm{OH}, \mathrm{NH}, \mathrm{N}^{+}, \mathrm{H}_{\alpha}, \mathrm{N}$ and $\mathrm{H}_{\beta}$ are observed at 309, 336, 463, 486, 496, and $656 \mathrm{~nm}$, respectively. Strong emissions from $\mathrm{NH}_{2}$ radicals are observed at 525, 543, 569, 603, 629, and $663 \mathrm{~nm}$ in all OES spectra from resonantly excited $\mathrm{NH}_{3}$ flows, indicating effective dissociation of $\mathrm{NH}_{3}$ molecules. 
Obviously increased emission intensities of $\mathrm{OH}, \mathrm{NH}, \mathrm{NH}_{2}, \mathrm{~N}, \mathrm{~N}^{+}$, and $\mathrm{H}$ are observed at the resonant wavelength of $9.219 \mu \mathrm{m}$. However, only very weak emission intensities of $\mathrm{NH}$ and $\mathrm{NH}_{2}$ radicals are identified when irradiated at the nonresonant wavelength of $10.591 \mu \mathrm{m}$. No emission peak is observed at the nonresonant wavelength of $9.201 \mu \mathrm{m}$.

$\mathrm{N}, \mathrm{NH}$, and $\mathrm{NH}_{2}$ are active nitrogen species for growing GaN. ${ }^{20,21,40}$ Growth of high-quality GaN films requires a sufficient supply of active nitrogen and gallium species by cracking $\mathrm{NH}_{3}$ and $\mathrm{TMGa}$ molecules respectively, and transporting atomic $\mathrm{N}$ and Ga to proper lattice sites. The dissociation energies for dissociating TMGa into active gallium species has been reported to be much lower than that of $\mathrm{NH}_{3}{ }^{20,21}$ It is found that with the laser photons, the TMG molecules undergo fragmentation with relative ease in analogy with their thermolytic instability. ${ }^{20,21,41}$ However, effective decomposition of $\mathrm{NH}_{3}$ molecules requires a high temperature around $1000{ }^{\circ} \mathrm{C}$, which also leads to increased parasitic reactions, GaN decomposition and $\mathrm{N}$ escaping. ${ }^{13}$ Therefore, decomposing $\mathrm{NH}_{3}$ at an appropriate temperature is essential for growing high-quality GaN.

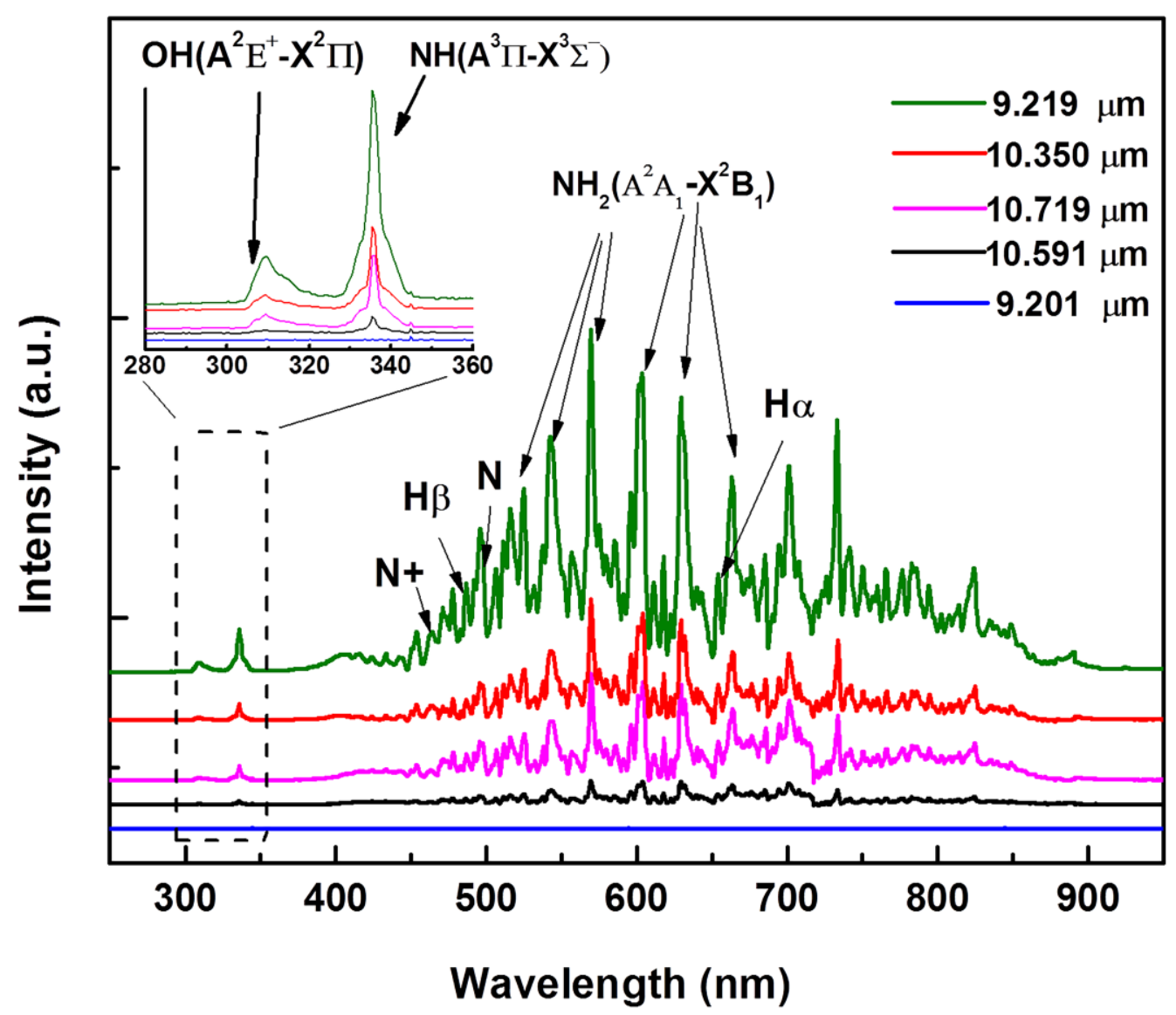

FIG.8. Optical emission spectra of the $\mathrm{NH}_{3}$ under laser irradiation at different wavelengths in open air.

It is generally believed formation of GaN in MOCVD includes four key steps: ${ }^{13,40}$ (i) TMGa: $\mathrm{NH}_{3}$ adduct formation, (ii) amide formation and methane elimination, (iii) trimer formation, and (iv) decomposition reaction and creating $\mathrm{N}$ and $\mathrm{Ga}$ to form GaN. 
The first gas-phase reaction is a spontaneous reaction between $\mathrm{TMGa}$ and $\mathrm{NH}_{3}$ to form a stable adduct $\left[\left(\mathrm{CH}_{3}\right)_{3} \mathrm{Ga}: \mathrm{NH}_{3}\right]$. It is reported that the formation of the adduct as parasite reaction significantly degrades GaN film quality and growth rate at high temperatures. ${ }^{13,21,40}$ The amide formation, trimer formation and decomposition reaction can be expressed by equations (2), (3) and (4), respectively: $:^{13,40}$

$\left(\mathrm{CH}_{3}\right)_{3} \mathrm{Ga}+\mathrm{NH}_{3} \rightarrow\left(\mathrm{CH}_{3}\right)_{3} \mathrm{Ga}: \mathrm{NH}_{3}$

$\left(\mathrm{CH}_{3}\right)_{3} \mathrm{Ga}: \mathrm{NH}_{3} \rightarrow\left(\mathrm{CH}_{3}\right)_{2} \mathrm{Ga}: \mathrm{NH}_{2}+\mathrm{CH}_{4}$

$3\left[\left(\mathrm{CH}_{3}\right)_{2} \mathrm{Ga}: \mathrm{NH}_{2}\right] \rightarrow\left[\left(\mathrm{CH}_{3}\right)_{2} \mathrm{Ga}: \mathrm{NH}_{2}\right]_{3}$

$\left[\left(\mathrm{CH}_{3}\right)_{2} \mathrm{Ga}: \mathrm{NH}_{2}\right]_{3} \rightarrow 3 \mathrm{GaN}+6 \mathrm{CH}_{4}$

The OES results indicate that the resonant vibrational excitation effectively dissociates $\mathrm{NH}_{3}$ molecules and increases the concentrations of the active nitrogen species, i.e. $\mathrm{N}, \mathrm{NH}$, and $\mathrm{NH}_{2}$. Based on the reported 4-step mechanism, effective decomposition of $\mathrm{NH}_{3}$ is suggested to reduce the formation of the $\mathrm{TMGa}: \mathrm{NH}_{3}$ adduct ${ }^{21}$ in the first step and decrease the energy barriers for the rest of the steps, and therefore results in the increased GaN growth rate.

It is noteworthy that performance of a GaN-based device is limited by parasitic defect-induced emission, such as the yellow luminescence observed in $\mathrm{GaN} .{ }^{42,43}$ Unintentionally doped $\mathrm{GaN}$ is generally a n-type semiconductor due to a high concentration of shallow donor $\mathrm{Si}_{\mathrm{Ga}}$ and $\mathrm{O}_{\mathrm{N}}{ }^{43} \mathrm{It}$ is reported that $\mathrm{H}$ radicals can form neutral complexes with shallow donors and acceptor dopants. These reactions help eliminating oxygen impurities, reducing impurity density and increasing in carrier mobility and resistivity of gallium nitride films. ${ }^{42}$ Considering the concentration of atomic hydrogen resulted from $\mathrm{NH}_{3}$ decomposition, oxygen impurities in $\mathrm{GaN}$ are expected to be reduced. It is suggested that with the increments of $\mathrm{H}$ radicals, Figure 8, the GaN crystalline quality and carrier mobility increase under resonant excitations, compared to those at nonresonant wavelengths.

Therefore GaN films of better crystalline quality, lower impurity densities, and high deposition rates are obtained under resonant vibrational excitation. The results are in good accordance with the SEM, Raman, and XRD results.

\section{CONCLUSION}

In summary, vibrational excitations of $\mathrm{NH}_{3}$ molecules were studied using a tunable $\mathrm{CO}_{2}$ laser in growing crystalline GaN films on $\mathrm{Si}(100)$ substrates. The resonant vibrational excitation at $9.219,10.350$, and $10.719 \mu \mathrm{m}$ were more efficient than nonresonant excitation in dissociating $\mathrm{NH}_{3}$ molecules and enhancing the GaN deposition rate and quality. The OES results showed the resonant excitation of the NH-wagging modes modifies the synthesis process in a way that increases the supplies of $\mathrm{NH}, \mathrm{NH}_{2}, \mathrm{~N}, \mathrm{~N}^{+}$, and $\mathrm{H}$. This leads to the enhancement in GaN deposition rates 
and improvement in crystalline quality. The extremely high GaN growth rate of $\sim 84 \mu \mathrm{m} / \mathrm{h}$ with an improved crystalline quality was achieved under the resonant excitation at $9.219 \mu \mathrm{m}$. The red-shifts of the $\mathrm{E}_{2 \mathrm{H}}$ in Raman spectra indicate that the GaN films grown on Si suffer from tensile stress. The GaN films grown at the laser wavelengths of 9.219 $\mu \mathrm{m}$ exhibit the lowest stress. The FWHM value of the XRD rocking curves of GaN (0002) and GaN (10-12) diffraction peaks decreased at resonant depositions and reached its minimum values at $9.219 \mu \mathrm{m}$, indicating reduced TDs density. XRD $\omega$-FWHM of 45 arcmin for the $\mathrm{GaN}(0002)$ and of $53 \operatorname{arcmin}$ for the GaN(10-12) reflection were measured for samples grown at laser wavelength of $9.219 \mu \mathrm{m}$; the FWHMs of the GaN(0002) and GaN(10-12) planes are about 3-5 times broader than those of the best GaN epilayer samples reported in literature.$^{6}$ Further investigation are underway to improve the quality of the GaN films deposited via the LMOCVD techniques while maintain ing high growth rates.

\section{ACKNOWLEDGEMENTS}

This work was financially supported by the National Science Foundation (NSF CMMI 1068510 and 1129613). It was also performed in part in Central Facilities of the Nebraska Center for Materials and Nanoscience, which is supported by the Nebraska Research Initiative.

${ }^{1}$ A. Khan, K. Balakrishnan and T. Katona, Nature photonics 2, 77 (2008).

${ }^{2}$ A. Avramescu, T. Lermer, J. Müller, C. Eichler, G. Bruederl, M. Sabathil, S. Lutgen and U. Strauss, Applied physics express 3, 061003 (2010).

${ }^{3}$ Y.-F. Wu, D. Kapolnek, J. P. Ibbetson, P. Parikh, B. P. Keller and U. K. Mishra, Electron Devices, IEEE Transactions on 48, 586 (2001).

${ }^{4}$ S. Nakamura, S. Pearton, and G. Fasol, The blue laser diode: the complete story (Springer Science \& Business Media, 2013).

${ }^{5}$ D. Ehrentraut, E. Meissner, and M. Bockowski, Technology of gallium nitride crystal growth, Vol. 133 (Springer Science \& Business Media, 2010).

${ }^{6}$ H. Schenk, E. Frayssinet, A. Bavard, D. Rondi, Y. Cordier, and M. Kennard, Journal of Crystal Growth 314, 85 (2011).

${ }^{7}$ I. C. Kizilyalli, A. P. Edwards, O. Aktas, T. Prunty, and D. Bour, Electron Devices, IEEE Transactions on 62, 414 (2015).

${ }^{8}$ E. Frayssinet, Y. Cordier, H. D. Schenk, and A. Bavard, Physica Status Solidi. C: Current Topics in Solid State Physics 8, 1479 (2011).

${ }^{9}$ W. Luo, J. Wu, J. Goldsmith, Y. Du, T. Yu, Z. Yang, and G. Zhang, Journal of Crystal Growth 340, 18 (2012).

${ }^{10}$ D. Tomida, Y. Kagamitani, Q. Bao, K. Hazu, H. Sawayama, S. Chichibu, C. Yokoyama, T. Fukuda, and T. Ishiguro, Journal of Crystal Growth 353, 59 (2012).

${ }^{11}$ Y. Mori, M. Imade, M. Maruyama, and M. Yoshimura, ECS J. Solid State Sci. Technol. 2, N3068 (2013).

${ }^{12}$ R. Collazo, S. Mita, A. Aleksov, R. Schlesser, and Z. Sitar, Journal of crystal growth 287, 586 (2006).

${ }^{13}$ I. M. Watson, Coordination Chemistry Reviews 257, 2120 (2013).

${ }^{14}$ J. R. Creighton, G. T. Wang, and M. E. Coltrin, Journal of Crystal Growth 298, 2 (2007).

${ }^{15}$ D. Zhao, J. Zhu, D. Jiang, H. Yang, J. Liang, X. Li, and H. Gong, Journal of Crystal Growth 289, 72 (2006).

${ }^{16}$ A. Thon and T. Kuech, Applied physics letters 69, 55 (1996). 
${ }^{17}$ H. Choi, M. Cheong, M. Rana, S. Chua, T. Osipowicz, and J. Pan, Journal of Vacuum Science \& Technology B 21, 1080 (2003).

${ }^{18}$ D. Koleske, A. Wickenden, R. Henry, J. Culbertson, and M. Twigg, Journal of crystal growth 223, 466 (2001).

${ }^{19}$ Y. Lin, S. Zhou, W. Wang, W. Yang, H. Qian, H. Wang, Z. Lin, Z. Liu, Y. Zhu, and G. Li, Journal of Materials Chemistry C 3, 1484 (2015).

${ }^{20}$ B. Zhou, Z. Li, T. Tansley, and K. Butcher, Journal of crystal growth 160, 201 (1996).

${ }^{21}$ Y. Zhou, B. Shen, Z. Chen, P. Chen, R. Zhang, Y. Shi, and Y. Zheng, IEEE, p. 701 (1998).

${ }^{22}$ H. Rabiee Golgir, Y. Gao, Y. S. Zhou, L. Fan, P. Thirugnanam, K. Keramatnejad, L. Jiang, J.-F. Silvain, and Y. F. Lu, Crystal Growth \& Design 14, 6248 (2014).

${ }^{23}$ M. N. A. Rahman, Y. Yusuf, M. Mansor, and A. Shuhaimi, Applied Surface Science 362, 572 (2016).

${ }^{24}$ M. K. Ozturk, E. Arslan, İ. Kars, S. Ozcelik, and E. Ozbay, Materials Science in Semiconductor Processing 16, 83 (2013).

${ }^{25}$ T. N. Bhat, M. K. Rajpalke, B. Roul, M. Kumar, and S. Krupanidhi, Journal of Applied Physics 110, 093718 (2011).

${ }^{26}$ Y. Nakada, I. Aksenov, and H. Okumura, Applied physics letters 73, 827 (1998).

${ }^{27}$ K.-C. Shen, M.-C. Jiang, H.-R. Liu, H.-H. Hsueh, Y.-C. Kao, R.-H. Horng, and D.-S. Wuu, Optics express 21, 26468 (2013).

${ }^{28}$ L. Fan, Z. Q. Xie, J. Park, X. N. He, Y. Zhou, L. Jiang, and Y. Lu, Journal of Laser Applications 24, 022001 (2012).

${ }^{29} \mathrm{C}$. W. David, Journal of chemical education 73, 46 (1996).

${ }^{30}$ J. McBride, and R. Nicholls, Journal of Physics B: Atomic and Molecular Physics 5, 408 (1972).

${ }^{31}$ H. R. Golgir, Y. Gao, Y. Zhou, L. Fan, K. Keramatnejad, and Y. Lu, EFFECT OF LASER-ASSISTED RESONANT EXCITATION ON THE GROWTH OF GaN FILMS, 33nd International Congress on Applications of Lasers and Electro-Optics, ICALEO 2014 (2014).

${ }^{32} \mathrm{P}$. Thirugnanam, Y. Zhou, H. Golgir, Y. Gao, and Y. Lu, Synthesis of gallium nitride nanoplates using laser-assisted metal organic chemical vapor deposition, 32nd International Congress on Applications of Lasers and Electro-Optics, ICALEO 2013 (2013).

${ }^{33}$ D. Ghosh, S. Hussain, B. Ghosh, R. Bhar, and A. Pal, ISRN Materials Science 2014 (2014).

${ }^{34}$ M. P. Chowdhury, R. Roy, B. Chakraborty, and A. Pal, Thin solid films 491, 29 (2005).

${ }^{35}$ M. Kuball, Surface and Interface Analysis 31, 987 (2001).

${ }^{36}$ C. Kisielowski, J. Krüger, S. Ruvimov, T. Suski, J. Ager III, E. Jones, Z. Liliental-Weber, M. Rubin, E. Weber, and M. Bremser, Physical Review B 54, 17745 (1996).

${ }^{37}$ M. Moram, and M. Vickers, Reports on Progress in Physics 72, 036502 (2009).

${ }^{38}$ E. Arslan, M. K. Ozturk, A. Teke, S. Ozcelik, and E. Ozbay, Journal of Physics D: Applied Physics 41, 155317 (2008).

${ }^{39}$ Z. Q. Xie, X. N. He, W. Hu, T. Guillemet, J. B. Park, Y. S. Zhou, J. Bai, Y. Gao, X. C. Zeng, L. Jiang, and Y. F. Lu, Crystal Growth \& Design 10, 4928 (2010).

${ }^{40}$ R. P. Parikh, and R. A. Adomaitis, Journal of crystal growth 286, 259 (2006).

${ }^{41}$ S. S. Lee, S. M. Park, and P. J. Chong, Journal of Materials Chemistry 3, 347 (1993).

${ }^{42}$ S. Pearton, J. Zolper, R. Shul and F. Ren, Journal of applied physics, 86, 1 (1999).

${ }^{43}$ M. A. Reshchikov, and H. Morkoc, Journal of applied physics 97, 061301 (2005). 